\title{
Study on Coordination Mechanism Joint Distribution Based on Supply Chain Management
}

\author{
Guogang $\mathrm{Li}^{\mathrm{a}}$, Jiarong Liu ${ }^{\mathrm{b}}$ \\ School of Tianjin University of technology, Tianjin 300384, China \\ alggcj@163.com, b15222833831@163.com
}

Keywords: supply chain management, joint distribution, Nash bargaining model.

\begin{abstract}
With the rapid development of the free competitive market economy, the competition among enterprises become more and more fierce, seeking to competition in cooperation and the development to in competition. More and more companies introduce the idea of supply chain management, so that supply and requisitioning parties can share their information and then they will achieve win-win situation. This paper is based on the view of supply chain management to analysis the coordination mechanism joint distribution of the materials. Nash negotiation model is used to allocate the total benefits. At last, the paper illustrate the supply chain as a whole which can improve the income level of the cooperation of the parties, and it also can improve the service of customer.
\end{abstract}

\section{Introduction}

With the development of society and technology, enterprise's business environment and the way of production management has undergone great changes, on the one hand the customer's demand become more and more personalized and diversified; on the other hand the companies increasingly fine division of labor and specialization and growing complexity of supply. Therefore, the operations of the management of the border had to be from regard the enterprise as a unit in the past to evolve with the supply chain as a unit, in order to achieve a rapid response to the market. And then competition between enterprises will change into among the supply chain, so the cooperation between enterprises has become the supply chain cross-chain collaboration. It will become an inevitable choice for enterprises using supply chain to be the management model for the border. In order to make all the cooperation in the supply chain companies be benefit and increase their competitiveness, so it become a supply chain management ${ }^{[1]}$.

In recent years, supply chain management has been great concern to people at home and abroad of academics and business, and it achieved great success in practice. Not only is the internationally renowned multinational enterprise, major company such as Nike, Hewlett-Packard and Dell. They got great achievements in supply chain management, and reduced operating costs greatly, at the same time they improved operational efficiency and enhanced the competitiveness. Some domestic minor enterprise actively explore for supply chain management model what they operate, they rely on local industrial cluster and then do local integrated supply chain vertical cooperation and coordination across the chain horizontal. It enhance the company's agility greatly which is cluster of supply chain management ${ }^{[2]}$. .At the same time, user demand increases uncertainty and personalization, which pose a new challenge for the survival of the enterprise. Many enterprises has realized that competition in the market solely on their own are not enough because that enterprises are facing opponents may not be a business, but a supply chain upstream and downstream of all enterprises ${ }^{[3]}$. The vast majority of the supply chain study mentioned supply chain management to establish a win-win relationship, but for companies added to enhance the supply chain to bring the overall interests of the supply chain, whether all of the supply chain in which the participating companies have equal access to benefits is unknown ${ }^{[4]}$. From the retailer's point of view, the joint distribution can first reduce logistics costs, because the joint distribution by a number of retailers, they can spread the cost; third-party logistics services from the company's point of view, the joint distribution can also reduce their costs, thereby 
indirect cost savings to customers ${ }^{[5]}$. Therefore, the development of joint distribution has important economic and social significance.

The relationship of supply chain is supply-demand relation, if the vendor and the retailer can keep cooperative and consistency, the vendor and the retailer can share the benefits and avoid waste, and they can improve their services. Supply chain need to coordinate activities between the various supply chain enterprises as a whole, so it can achieve the best overall performance. The purpose of coordination is to meet the information of certain quality of service what it requires, and then it can passed in the supply chain seamlessly and smoothly, so that the supply chain could response to customer demand timely. Therefore, it is necessary to establish an effective coordination mechanism for the supply chain inventory management between the various nodes of the supply chain. The enterprises need establish an effective coordination if it will process effective coordination and cooperation. From the viewpoint of the entire supply chain to consider the establishment of coordination mechanism between the upstream and downstream enterprises, the use of Nash Bargaining solution model is constructed to analyze the joint distribution of benefits.

\section{Discussed problems and the setting of Nash negotiation model}

This paper is studying a problem of cost distribution issues which include suppliers, manufacturers, and vendors to go on the joint distribution. It is impossible of Basing on the supply chain and distribution mechanisms for cooperation alone, it need the support of third-party logistics companies. Therefore such joint distribution depends on large-scale logistics enterprises, and the co-distribution model need coordinate each other of supply chain enterprises.

Suppose the set of $n$ companies $N=\{1,2, \cdots, n\}$, and use a closed set $F$ of n-dimensional space represents a viable utility payments vector set. Suppose the cost that each enterprise required to carry out the joint distribution is $C=\left\{c_{1}, c_{2}, \cdots, c_{n}\right\}, X=\left\{x_{1}, x_{2}, \cdots, x_{n}\right\}$ is the cost that each enterprise carrying out the joint distribution, so $\sum_{i \in N} x_{i}-C(N)=0,0<x_{i}<c_{i}$. In the formula, $\mathrm{C}(\mathrm{N})$ is the cost of the joint distribution ${ }^{[6]}$. According to Nash bargaining theory, which may be defined as the negotiation solution $\prod_{i \in N}\left(c_{i}-x_{i}\right)$ enables Nash maximize product only strong and effective vector $\mathrm{X}$, $\mathrm{X}$ is selected to meet from $\mathrm{F}$ for all $i$ that meet $x_{i}<c_{i}$ each vector. Nash product represents a cost-saving value of the product of each enterprise, while maximizing the Nash product is to make the joint distribution enterprises understand maximize cost savings. Thus, by solving the following nonlinear programming problem can get the optimal solution $\mathrm{X}$.

$$
\begin{aligned}
& \max \prod_{i \in N}\left(c_{i}-x_{i}\right) \\
& \text { s.t. } \sum_{i \in N} x_{i}-C(N)=0 \\
& 0<x_{i}<c_{i}
\end{aligned}
$$

\section{Nash bargaining solution}

Measures in cooperation in multiplayer, supposing the player is $N=\{1,2, \cdots, n\}$, the players can share common interests by negotiate cooperation ${ }^{[7]}$. Suppose there are a series of negotiation programs which the two sides can choose options available, and they are the players from the two sides put forward their demands and corresponding measures (policies, actions) formation. All of these programs are feasible in practice. According to the basic setting of the Nash Bargaining solution, the negotiators finally will get a solution acceptable to all, suppose $X^{*}=\left\{x_{1}{ }^{*}, x_{2}{ }^{*}, \cdots, x_{i}^{*}, \cdots x_{n}{ }^{*}\right\}$ is the optimal solution, and it is the solution that Nash bargaining solution, then according to Kuhn-Tucker conditions ${ }^{[8]}$ : 


$$
\left\{\begin{array}{l}
-\prod_{i \in N, j \neq 1}\left(c_{i}-x_{i}^{*}\right)+\lambda+\mu=0 \\
-\prod_{i \in N, j \neq 2}\left(c_{i}-x_{i}^{*}\right)+\lambda+\mu=0 \\
\bullet \bullet \bullet \\
-\prod_{i \in N, j \neq i}\left(c_{j}-x_{j}^{*}\right)+\lambda+\mu=0 \\
\bullet \bullet \bullet \\
-\prod_{i \in N, j \neq n}\left(c_{i}-x_{i}^{*}\right)+\lambda+\mu=0 \\
\sum_{i \in N} x_{i}^{*}-C(N)=0 \\
x_{i}^{*}<c_{i} \\
\lambda, \mu>0
\end{array}\right.
$$

Thus equations can be drawn:

$$
\prod_{i \in N, i \neq 1}\left(c_{i}-x_{i}^{*}\right)=\prod_{i \in N, i \neq 2}\left(c_{i}-x_{i}^{*}\right)=\cdots=\prod_{j \in N, j \neq k}\left(c_{j}-x_{j}^{*}\right)=\cdots=\prod_{i \in N, i \neq n}\left(c_{i}-x_{i}^{*}\right), i \neq j
$$

The formula pairwise comparison, expand and simplify the formula can be obtained $c_{i}-X_{i}^{*}=c_{j}-X_{j}^{*}, i \neq j$

Both sides were summed available

$$
n\left(c_{i}-x_{i}^{*}\right)=\sum c_{j}-\sum x_{j}^{*}
$$

Since $\sum_{i \in N} x_{i}^{*}-C(N)=0$

So $X_{i}^{*}=c_{i}-\frac{1}{n}\left(\sum c_{j}-\sum X_{j}^{*}\right)=c_{i}-\frac{1}{n}\left(\sum c_{j}-C(N)\right)$

Nash negotiation solution can be obtained as follows:

$$
x_{i}^{*}=c_{i}-\frac{1}{n}\left(\sum_{i \in N} c_{i}-C(N)\right)
$$

\section{4. model application}

Assumed in the supply chain, there are three suppliers 1, 2, 3 distribute goods to a seller $\mathrm{M}$ as shown in Fig 1. Three suppliers of distribution volume are 8 tons, 11 tons and 5 tons. Assume the distribution fee formula is:

Cost $=$ tonnage $\times$ unit transportation costs $\times$ mileage. The unit transportation costs as shown in Table 1.

Table 1 cargo unit transportation costs table Unit (yuan / ton. Km)

\begin{tabular}{|c|c|c|c|c|c|}
\hline tonnage & 5 & 8 & 11 & 13 & 24 \\
\hline unit transportation costs & 2.8 & 2.4 & 2.1 & 1.9 & 1 \\
\hline
\end{tabular}




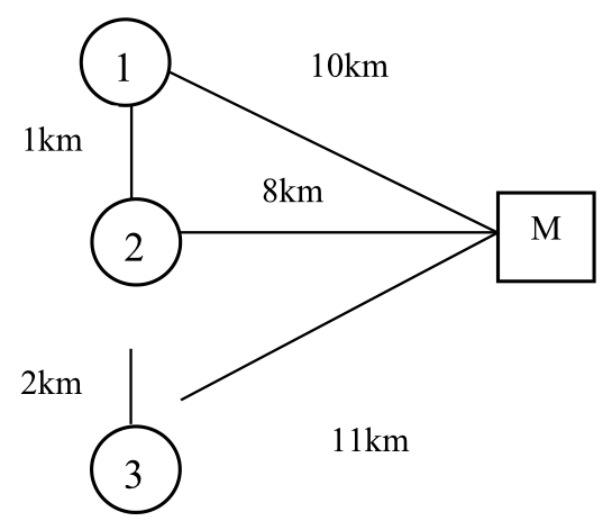

Figure 1 Distribution Figure

(1) If the three distribution enterprises distribute independently, then the fee is:

$\mathrm{C} 1=8 \times 2.4 \times 10=192$

$\mathrm{C}_{2}=11 \times 2.1 \times 8=184.8$

$\mathrm{C}_{3}=5 \times 2.8 \times 11=154$

The total distribution costs is $\mathrm{C}=192+184.8+154=530.8$

(2) If the three distribution enterprises choose joint distribution, then the cost is:

$\mathrm{C}=8 \times 2.4 \times 1+5 \times 2.8 \times 2+24 \times 1 \times 8=239.2$

It can be seen, the cost joint distribution is lower than independent distribution, and the problem this paper discussed is how to distribute joint distribution cost, namely 239.2 apportioned.

Suppose $X^{*}=\left\{x_{1}^{*}, x_{2}{ }^{*}, \cdots, x_{i}^{*}, \cdots x_{n}{ }^{*}\right\}$ is the Nash Bargaining solution what we need, according to the Nash Bargaining Solution we can get the solution as shown following:

$$
x_{i}^{*}=c_{i}-\frac{1}{n}\left(\sum_{i \in N} c_{i}-C(N)\right)
$$

Then three distribution enterprises assessed their costs are:

$$
\begin{aligned}
& x_{1}=192-\frac{1}{3}(530.8-239.2)=94.8 \\
& x_{2}=184.8-\frac{1}{3}(530.8-239.2)=87.6 \\
& x_{3}=154-\frac{1}{3}(530.8-239.2)=56.8
\end{aligned}
$$

\section{Benefit Analysis}

Cost Analysis

According to calculation example it can be seen, when the three suppliers distribute alone, their distribution costs are 192, 184.8, and 154. When the three enterprises choose cooperation and joint distribution, their distribution costs are 94.8, 87.6 and 56.8. Each enterprise distribution costs is much lower the share of distribution alone. This distribution pattern is visible both to ensure complementary advantages, we can maximize the synergy effect.

Service Improvement Analysis

When dealing with customers and suppliers, customers have many expectations, including not only the general expectations of the logistics operation, but also the communication, credibility, security, detailed understanding of customer and supplier reliability of operation and fast response expect other capabilities ${ }^{[9]}$. From the perspective of supply chain cooperation mechanisms, the distribution is not actually suppliers, manufacturers, vendors of the core business, if you build a joint distribution cooperation mechanism, leading jointly by the third party logistics and distribution, so 
the supply chain upstream and downstream enterprises we will have more time and energy on their core business, in order to meet customer needs to customer satisfaction, you can save the joint distribution costs for cargo delivery availability, improve service quality and service capabilities.

\section{Summary}

In the competitive market economy time, especially in the era of the Internet economy choose the right partner and a reasonable cost-benefit allocation method is very important. Logistics and distribution is an important link, select an appropriate distribution model can avoid many problems. Therefore, if an enterprise wants to improve their operational capacity, the low cost in terms of distribution, high efficiency model is feasible. The establishment of such a cooperation mechanism on the supply chain as a whole, to achieve a common distribution. Based on supply chain cooperation mechanisms, Nash bargaining solution applied to the supply chain and distribution enterprises to carry out cost-sharing, generally speaking, joint distribution is itself a cooperative mechanism, use Nash bargaining solution to establish cooperative model of joint distribution, by solving KT nonlinear programming problem to find solutions negotiations Nash, namely cost allocation sub-optimal solution, in order to determine the joint distribution of cost allocation plan.

\section{References}

[1]Li Ma. Several Stochastic Inventory Model Based on Supply Chain. Shandong Normal University. 2008.p.1

[2]Jizi Li, Shihua Ma. Supply Chain Management. China Machine Press.2010. p.1

[3]Shuang Zhang. The Study on Cooperation Mechanism among Supply Chain Enterprises. Northeast Forestry University. 2007. p.1

[4]Mian Zhang, Wei Zhao. Supply chain business culture consistent impact on supply chain effects Compare the supply chain from the upstream and downstream enterprises. Enterprise Strategy.2014. p.1

[5]Xiaochun Tang, Yinlong Wu, Liang Zhao. Common Development and Global Distribution of China's Development Prospects. Highway and Transportation Research.2013. p.2

[6]Fuguang Bao, Daqiang Chen. Research on Supply Chain Coordination and Benefit Distribution Integrated into TPL Service Level. Railway Transport and Economy.2013. p.2

[7]Shengyu Zhang, Dingpi Hou. The Nash -bargaining Solution of Finance Exchange. Operrations Research and Man Agement Science.2000. p.2

[8]Chunhua Ju, Chunyuan Gao. Study of Cost Allocation Model of Common Delivery Based on Multiple Methods. Railway Transport and Economy.2009. p.3

[9]Juan Chan, Yongsheng Han, Yanping Liu. Urban Logistics Delivery Model and System Architecture Design. Urban Insight.2013. p.4 